\title{
Perception Exercise self-efficacy, Body Image and Health-related Quality of Life of Children with Needs Special Education
}

\author{
Pervin TOPTAŞ DEMİRCI* \\ Erdemli Department of Tourism Animation, Mersin University, Turkey \\ *Corresponding author: pervindemirci36@ hotmail.com
}

\begin{abstract}
In this study, it was aimed to examine the body 1mage, exercise self-efficacy and health-related quality of life of children with special education needs. Participants of this study were selected from volunteer students in five and eight classes in state school in Mersin during the 2016-2017 academic year. The study group consists of a total of 95 students, 52 of which require special education and 43 of which are healthy. The Health Related Quality of Life Scale (Kid-KINDL) was used to describe the quality of life of healthy and specialist training groups, the Exercise Self-Efficacy Scale (ESS) and the Body Image Scale (BIS) were used to determine exercise levels. According to findings; When the groups' physical characteristics were compared, a significant difference wasn't observed in terms of age between them $(\mathrm{p}>0.05)$. However, when compared with healthy group special education group body height, weight and BMI, there was a significant difference at $p<.001$ level. There was not significant difference between the groups in the friendship subscale of the HRQL-KINDL scale ( $p>0.05$ ). However, the total quality of life, physical well-being, emotional well-being, school, self-esteem and family subscales scores of the healthy group were significantly higher than the special education group $(\mathrm{p}<0.001)$. Similarly, healthy group ESL and BIS were found to be higher than special education group $(\mathrm{p}<0.001)$. As a result of this study, it was seen that the of health group have higher exercise self-efficacy and body image and health-related quality of life than special education group.
\end{abstract}

\section{Keywords}

Exercise Self-Efficacy, Quality Of Life, Body Image, Special Education

\section{INTRODUCTION}

Life quality; it is expressed as an individual response to the physical, mental and social influences of the problems affecting individual happiness within a particular habitat, as well as subjective expressions of various aspects of life (Beal et al., 2004). Quality of life refers to how people view the positive and negative aspects of their lives as subjective, and includes psychological and physical factors that influence the perceived satisfaction of people in their general life (Diener et al., 1999; Petersson et al., 2013). Quality of life is a comprehensive concept that includes personal well-being beyond personal health. Health-related quality of life can be expressed by the physical, mental and social influences of discomforts affecting individual satisfaction under specific living conditions, as an individual response in daily life. For this reason, the measurement of quality of life has a broader concept and understanding when compared to health status criteria (Orley et al., 1993; Eser et al., 2008). Regardless of mental capacity, exercise for all children is considered an important health tool. Physical activity is necessary for the individual to have physical development, coordination, growth, motivation, socialization and a healthy body (American Academy of Pediatrics, 1987). Selfefficacy is the theory that individual behavior motivation have a strong influence in achieving goals successfully. Self-efficacy in Bandura's theory $(1997,2001)$ is defined as "belief in the ability of the person to organize and conduct the action necessary to manage possible situations" (Bandura, 1995).

According to the results of the studies to investigate the relation between self-efficacy and exercise and physical activity; demonstrating the importance of self-sufficiency in contributing to success in these events (Weiss ve Ferrer-Caja, 
2002). For example, it has been shown that the amount of exercise and physical activity in children is associated with physical self-efficacy scores (McAuley ve Blissmer, 2000; Strauss et al., 2001). The body image refers to self-evaluation of the person's body appearance (Alzubaidi \& Kazem, 2013). However, some researchers have suggested that body image is a much more dimensional concept consisting of separate assessments in certain areas (such as health and physical fitness, face and general appearance, physical and muscle strength) as well as global health assessments (Cash \& Pruzinsky, 2004). Cusack (2000) also defines body image as a multidimensional self-attitude toward one's body. Over the past few years, research on body image has become extremely important as a result of emphasizing physical attraction as well as the interest of one's body image. Both health beliefs and body image and important factors such as gender, exercise and athletic participation have been recorded as factors affecting them (Woodrow-Keys 2006; Beller 2007). In this study, it was aimed to examine the body 1mage, exercise self-efficacy and health-related quality of life of children with special education needs.

\section{MATERIALS AND METHODS}

\section{Participants}

Participants of this study were selected from volunteer students in five and eight classes in state school in Mersin during the 2016-2017 academic year. The study group consists of a total of 95 students, 52 of which require special education and 43 of which are healthy. The study was conducted in accordance with the Helsinki declaration (WMADH (2000).

\section{Data Collection Tools}

Body Respect (BE) refers to the selfevaluation of a person's body or appearance and is measured by the body image scale. Consisting of 18 items, the Exercise Self-Efficacy Scale (ESS) that was developed by Bandura (Bandura, 1997) and expressed in 0-100 scores was used in order to define the exercise levels while Kid-KINDL Health-Related Quality of Life (HRQL) was used to assess the health-related quality of life.

\section{Exercise Self-Efficacy Scale (ESS)}

Exercise Self-Efficacy Scale measures a person's perceived self-efficacy confidence. The scale is a measure of self-statement and consists of 18 self-efficacy items that require the subjects to show their confidence in performing the physical activities and exercises. Exercise Self-Efficacy Scale was developed by Bandura and its validity and reliability studies were carried out by Bozkurt with the patients with breast cancer in Turkey. The test-retest reliability coefficient was found 0.968 (Bandura, 1997; Bozkurt, 2009). ES Scale consists of 18 items that can be scored between $0 \%$ and $100 \%$. The participants are scored by 100 points with 10-unit intervals ranging from 0 to 50 ("Moderately certain can do") and 100 ("Highly certain can do") according to the level or power of confidence in their self-efficacy. The internal consistency reliability was found 0.94 (Bozkurt, 2009).

\section{Body Image Scale (BIS)}

The Body Image Scale (BIS) was developed by Secard \& Jurard in 1953 . This is a measure of satisfaction with 40 distinct body parts or functions of the body. The scale used in our country is a five-point Likert type measure consisting of 40 items. The most positive expression is 1 point, the most negative is 5 points. Accordingly, the lowest possible total score is 40 and the highest total score is 200. The increase in the total score means that the satisfaction of the person decreases and the scores decrease, which means that the satisfaction of the person increases (Robinson and Post, 1995).

\section{Health-Related Quality of Life Scale (Kid- KINDL)}

Developed specially for children and adolescents by Ravens- Sieberer and Bullinger in 1998 ,

KINDL

(KINDer

Lebensqualitätsfragebogen: Children Quality of Life Questionnaire) is an instrument for measuring general-purpose quality of life. KINDL was developed in the German language and translated into 14 languages. Eser et al. performed the validity and reliability studies of the scale for the Turkish language for the children aged between 8 and 12 (Eser et aal., 2008). The questionnaire has 24 items and sub-dimensions including 5-likert options. The scale includes six sub-dimensions including physical well-being, emotional wellbeing, self-esteem, family, friends and school (school or nursery school/kindergarten for 
everyday functioning). Each sub-dimension has 4 items. While the scores for the sub-dimensions are independently calculated, these six sub-dimensions are combined to produce a score of total quality of life. The scores obtained from the scale range between 0 and 100 . The scale doesn't have any breakpoint. Getting high score means well-being in quality of life. The items of Kid-KINDL are ranged from 1 (never) to 5 (all the time) and scaled with likert-type measure.

\section{Statistical Analysis}

All statistical analyses were performed by SPSS version 18 Results of descriptive statistics in this study are presented as mean, standard deviation rates. Mann Whitney U test was used for the paired comparisons because the data doesn't have a normal distribution. The fact that $\mathrm{p}$ was less than 0.05 was considered significant.

\section{RESULTS}

The Healthy Group mean values of participants were $11.92 \pm 0.85$ years for age, $164.00 \pm 7.34 \mathrm{~cm}$ for body height, $46.24 \pm 5.06 \mathrm{~kg}$ for body weight and 21.65 \pm 2.26 for BMI, and Special Education Groups $12.26 \pm 0.78$ years for age, $\quad 155.00 \pm 6.36 \mathrm{~cm}$ for body height, $55.25 \pm 6.72 \mathrm{~kg}$ for body weight and $25.15 \pm 2.69$ for BMI respectively. (Table 1). When the groups' physical characteristics were compared, a significant difference wasn't observed in terms of age between them. However, when compared with healthy group special education groupbody height, weight and BMI, there was a significant difference at $\mathrm{p}<.001$ level (Table 1).

Table 1. Comparison of Physical Properties between Healthy Group and Special Education Groups.

\begin{tabular}{|c|c|c|c|c|c|c|}
\hline & & $\mathbf{N}$ & M. & SD. & $\mathrm{Z}$ değeri & $\begin{array}{c}\text { Asymp. } \\
\text { Sig. }\end{array}$ \\
\hline \multirow{3}{*}{ Age (Years) } & Healthy Group & 43 & 11.92 & 0.85 & \multirow{3}{*}{-.302} & \multirow{3}{*}{.763} \\
\hline & Special Education Group & 52 & 12.26 & 0.78 & & \\
\hline & Total & 95 & 9.95 & 0.81 & & \\
\hline \multirow{3}{*}{$\begin{array}{l}\text { Body Height } \\
\quad(\mathrm{cm})\end{array}$} & Healthy Group & 43 & 164.00 & 7.34 & \multirow{3}{*}{-3.244} & \multirow{3}{*}{$.001 * *$} \\
\hline & Special Education Group & 52 & 155.00 & 6.36 & & \\
\hline & Total & 95 & 159.50 & 6.85 & & \\
\hline \multirow{3}{*}{$\begin{array}{c}\text { Body Weight } \\
(\mathrm{kg})\end{array}$} & Healthy Group & 43 & 46.24 & 5.06 & \multirow{3}{*}{-2.125} & \multirow{3}{*}{$.001 * *$} \\
\hline & Special Education Group & 52 & 55.25 & 6.72 & & \\
\hline & Total & 95 & 49.24 & 5.89 & & \\
\hline \multirow{3}{*}{$\begin{array}{c}\text { Body Mass } \\
\text { İndex } \\
\text { (BMI) }\end{array}$} & Healthy Group & 43 & 21.65 & 2.26 & \multirow{3}{*}{-4.397} & \multirow{3}{*}{$.001 * *$} \\
\hline & Special Education Group & 52 & 25.15 & 2.69 & & \\
\hline & Total & 95 & 22.90 & 2.47 & & \\
\hline
\end{tabular}

** $\mathrm{p}<0.01$ level, Mann Whitney U Test=MW U Test

The scores and total quality of life scores (Total HRLQ), ESL and BIS scores obtained from the subscales of the Kid-KINDL scale scale for both groups were given (Table 2). There was no significant difference between the groups in the friendship subscale of the HRQL-KINDL scale (p>0.05) (Table 2). However, the total quality of life, physical well-being, emotional well-being, school, self-esteem and family subscales scores of the healthy group were significantly higher than the special education group ( $p<0.001)$. Similarly, healthy group ESL and BIS were found to be higher than special education group $(\mathrm{p}<0.001)$ (Table 2). 
Table 2. Healthy Group and Special Education Group Children's Perceptions on Health-Related Quality of Life, Body Image and Exercise Self-Efficacy Levels

\begin{tabular}{|c|c|c|c|c|c|}
\hline Dimensions & Group & $\mathbf{N}$ & $\mathrm{X} \pm \mathrm{SS}$ & $Z$ değeri & $\begin{array}{c}\text { Asymp. } \\
\text { Sig }\end{array}$ \\
\hline \multirow{3}{*}{$\begin{array}{l}\text { Physical Well- } \\
\text { Being }\end{array}$} & Healthy Group & 43 & $17.33 \pm 2.53$ & \multirow{3}{*}{-1.738} & \multirow{3}{*}{$.001 * *$} \\
\hline & Special Education Group & 52 & $8.72 \pm 2.91$ & & \\
\hline & Total & 95 & $13.01 \pm 2.72$ & & \\
\hline \multirow{3}{*}{$\begin{array}{c}\text { Emotional } \\
\text { Well-Being }\end{array}$} & Healthy Group & 43 & $14.21 \pm 2.54$ & \multirow{3}{*}{-1.535} & \multirow{3}{*}{$.003 * *$} \\
\hline & Special Education Group & 52 & $10.43 \pm 2.26$ & & \\
\hline & Total & 95 & $12.32 \pm 2.40$ & & \\
\hline \multirow{3}{*}{ Self-Esteem } & Healthy Group & 43 & $14.12 \pm 2.58$ & \multirow{3}{*}{-1.395} & \multirow{3}{*}{$.005 * *$} \\
\hline & Special Education Group & 52 & $9.15 \pm 2.35$ & & \\
\hline & Total & 95 & $11.68 \pm 2.46$ & & \\
\hline \multirow{3}{*}{ Family } & Healthy Group & 43 & $16.18 \pm 2.76$ & \multirow{3}{*}{-1.455} & \multirow{3}{*}{$.004 * *$} \\
\hline & Special Education Group & 52 & $10.17 \pm 2.25$ & & \\
\hline & Total & 95 & $13.17 \pm 2.50$ & & \\
\hline \multirow{3}{*}{ Friends } & Healthy Group & 43 & $11.23 \pm 2.61$ & \multirow{3}{*}{,- 832} & \multirow{3}{*}{.321} \\
\hline & Special Education Group & 52 & $10.63 \pm 2.24$ & & \\
\hline & Total & 95 & $10.93 \pm 2.42$ & & \\
\hline \multirow{3}{*}{ School } & Healthy Group & 43 & $17.15 \pm 2.91$ & \multirow{3}{*}{-1.370} & \multirow{3}{*}{$.006 * *$} \\
\hline & Special Education Group & 52 & $11.96 \pm 2.32$ & & \\
\hline & Total & 95 & $14.55 \pm 2.61$ & & \\
\hline \multirow{3}{*}{ Total HRLQ } & Healthy Group & 43 & $15.03 \pm 2.65$ & \multirow{3}{*}{-1.345} & \multirow{3}{*}{$.007 * *$} \\
\hline & Special Education Group & 52 & $10.17 \pm 2.41$ & & \\
\hline & Total & 95 & $12.61 \pm 2.51$ & & \\
\hline \multirow{3}{*}{ ESS (puanı) } & Healthy Group & 43 & $75.5 \pm 14.3$ & \multirow{3}{*}{$-2,844$} & \multirow{3}{*}{, $001^{* \star}$} \\
\hline & Special Education Group & 52 & $48.2 \pm 10.4$ & & \\
\hline & Total & 95 & $61.8 \pm 12.3$ & & \\
\hline \multirow{3}{*}{ BIS (puanı) } & Healthy Group & 43 & $140.5 \pm 21.2$ & \multirow{3}{*}{$-1,275$} & \multirow{3}{*}{, $001^{* *}$} \\
\hline & Special Education Group & 52 & $165.5 \pm 19.3$ & & \\
\hline & Total & 95 & $153.0 \pm 20.2$ & & \\
\hline
\end{tabular}

( $>0.05), * * p<0.01$ level, Total Health-Related Quality of Life (Total HRLQ), Body Image Scale (BIS)

\section{DISCUSSION AND CONCLUSION}

HRQL is a multi-dimensional concept addressing to subjectivity. HRQL focuses on perception of physical, emotional, mental and social functions and the impact of health state on the quality of life (Demirci et al., 2017). American Academy of Paediatrics suggests that exercise is an important instrument for health for all children irrespective of their mental capacity. Physical activity is considered necessary for individual physical development, coordination, growth, motivation, socialisation and having a healthy body (American Academy of Pediatrics 1987).

In this study, it was aimed to examine the body 1mage, exercise self-efficacy and healthrelated quality of life of children with special education needs. In the study; When the groups' physical characteristics were compared, a significant difference wasn't observed in terms of age between them. However, when compared with healthy group special education groupbody height, 
weight and VKI, there was a significant difference at level. At the same time; the scores and total quality of life scores (Total HRLQ), ESL and BIS scores obtained from the subscales of the Kid-KINDL scale scale for both groups were given (Table 2). There was no significant difference between the groups in the friendship subscale of the HRQL-KINDL scale. However, the total quality of life, physical well-being, emotional well-being, school, self-esteem and family subscales scores of the healthy group were significantly higher than the special education group. Similarly, healthy group ESL and BIS were found to be higher than special education group.

In the study conducted by Çakar (Çakar 2011), the relationship between school and quality of life was investigated among 373 children who applied to elementary school and adolescents. HRQL scale for children and adolescents as data collection tool. This study found that there is a positive relationship between school life quality sub-dimensions, physical fitness, emotional wellbeing, family life, friendship, and school life. These results are parallel to some sub-dimensions in our findings. A school environment is one in which most of the children spend their days or develop sportive skills after school. Therefore, it has been put forward that various extracurricular possibilities need to be developed to improve the children's many learning requirements, quality of life and exercise levels. Over the last few years, research on body image has become increasingly important as a result of the emphasis on physical attractiveness, which is why one is engaged with the body image. Both health beliefs and body image and important factors such as gender, media, exercise and athletic participation have been recorded as important factors affecting them; There is a small, evolving literature available at present concerning the relationship between the two.

According to Woodrow-Keys (2006), although two concepts can not be interchanged, they are the center of effort, effort, and are associated with various correct health practices. Beller (2007) suggests that people who emphasize physical health may have some false beliefs that exacerbate the levels of distress. In another study in which HRQL was assessed for subscales of the Kid-KINDL quality of life scale, it was found that hearing impaired children had the highest score in the subscale of physical well-being and this finding is not statistically significant when compared with healthy children. On the other hand, it was determined that hearing impaired children had the lowest score of self-esteem among the subscales of the quality of life scale and that this difference was statistically significant compared to healthy children (Ekim and Ocakç1, 2012).

As a result; In the study, it was determined that the total quality of life, physical health status, emotional well-being, self-esteem and family subdimension of the healthy group increased significantly compared to the special education group. Similarly healthy group ESL and BIS were found to be higher than special education group. which children with needs special education are encouraged to improve their self-esteem and body sensation and to direct their sport in order to maintain self-confidence and independence in their daily life activities.

\section{REFERENCES}

American Academy of Pediatrics (1987). Exercise for children who are mentally retarded. Pediatrics, 180: 447-448.

Bandura A (1995). Exercise of personal and collective efficacy in changing societies. In: A. Bandura (Ed.), Self-efficacy in changing societies (pp. 1-45). New York: Cambridge University Press.

Bandura A (1997). Self-efficacy: The exercise of control. New York: Freeman.

Bandura A (2001). Social cognitive theory: An agentic perspective. Annual Review of Psychology, 52, 1-26.

Beal AC, Co JP, Dougherty D, Jorsling T, Kam J, Perrin J, Palmer RH (2004). Quality measures for children's health care, Pediatrics, 113 (2): 199-209.

Beller S. (2007). Beliefs and Physical Health, Available at beliefs. html. (accessed 22 of Mar).

Bozkurt N (2009). Investigation of the breast cancer patients exercise self- efficacy scale Turkish reliability and validity. Izmir: Ege University Institute of Health Sci.

Cash T \& Pruzinsky T (2004). Body Image: A handbook of Theory, Research and Clinical Practice. New York: Guilford Press.

Cusack L (2000). Perception of body image: Implications for the workplace. Employee Assistance Quarterly, 15, 23-38. 
Çakar F S (2011). School attachment and quality of life in children and adolescents of elementary school In Turkey, Educ Res; 1(9): 1465-1471.

Demirci N, Demirci Toptaş P, Demirci E (2017). The effect of school-based exercise practices of 9-11 year old girls students on obesity and health-related quality of life, Universal Journal of Educational Research 5(8): 13231331 ,

Diener E, Suh E M, Lucas R E, Smith H L (1999). Subjective well-being: Three decades of progress. Psych Bulletin, 123(2):276-303.

Eser F, Yüksel H, Baydur H, Erhart M, Saatlı G, Özyurt B C, Özcan C, Sieberer U R (2008). The Psychometric properties of the new Turkish generic health-related quality of life questionnaire for children (KidKINDL).Turkish Journal of Psychiatry; 19(4): 409-417.

Ekim A, Ocakçı A F (2012). Quality of life among hearing-impaired children aged 8-12 years. Ankara Health Services journal; Cilt 11, Say1 1.

Petersson C, Rune J, Simeonsson R J, Enskar K, Huus K (2013). Comparing children's selfreport instruments for health-related quality of life using the international classification of functioning, Disability and Health for Children and Youth (ICF-CY). Health and Qual of Life Out; 11:75; 1-10.

Orley J, Kuyken W (1993). Quality of life assessment: International perspectives. proceedings of the joint meeting organized by the who and the foundation IPSEN in Paris; 41-57.
McAuley E \& Blissmer B (2000). Self-efficacy and attributional processes in physical activity in: T. S. Horn (Ed.), Advances in sport psychology (2nd ed., pp. 185-205). Champaign, IL: Human Kinetics.

Robinson BE, Post P (1995). Work addiction as a function of family of origin and its influence on current family functioning. The Family Journal, 3; 200-206.

Strauss RS, Rodzilsky D, Burack G, and Colin M (2001). Psychological correlates of physical activity in healthy children. Archives of Pediatrics and Adolescent Medicine, 155, 807-902.

Weiss MR \& Ferrer-Caja E (2002). Motivational orientations and sport behavior. In: T. S. Horn (Ed.), Advances in sport psychology (2nd ed., pp. 101-183). Champaign, IL: Human Kinetics.

WMADH (2000). World Medical Association Declaration of Helsinki: Ethical Principles for Medical Research Involving Human Subjects. Journal of the American Medical Association. 284. pp. 3043- 3045.

Woodrow-Keys E (2006). The effect of body image on career decision-making selfefficacy and assertiveness in female athletes and non-athletes. Unpublished Master thesis, Marshal University, US. 